\title{
Superoxide dismutase in Cryptococcus neoformans varieties gattii, grubii, and neoformans
}

\author{
ALT Dias, MRPL Brigagão*, P Colepicolo**, AM Siqueira***, EG da Silva, CR Paula/ ${ }^{+}$
}

Departamento de Microbiologia, Instituto de Ciências Biomédicas II *Departamento de Ciências Exatas **Departamento de Bioquímica, Instituto de Química, Av. Professor Lineu Prestes 1374, 05508900 São Paulo, SP, Brasil ***Departamento de Ciências Biológicas, UNIFAL-MG, Alfenas, MG, Brasil

Some clear dissimilarities occur among the varieties of Cryptococcus neoformans but there are few studies about the differences among individual yeast antioxidant enzymes. The total superoxide dismutase (SOD) activities and the copper, zinc-depend SOD $(\mathrm{Cu}, \mathrm{ZnSOD})$ and manganese-dependent SOD (MnSOD) isoenzymes of five reference C. neoformans strains belonged to A, B, C, AD and D serotypes (Table I) and other nine C. neoformans isolates (Table II) were determined. There were significant differences $(\mathrm{p}<0.01$ and $\mathrm{p}<0.05)$ in total SOD activity among the varietie gattii (serotype $C$ ) and the other varieties. $C u, Z n S O D$ showed difference $(\mathrm{p}<0.05)$ between $A$ and $D$ serotypes. These results point out a variety and serotype-independent SOD activity in $\mathrm{C}$. neoformans reference strains and the other isolates that were evaluated.

Key words: Cryptococcus neoformans - superoxide dismutase - antioxidant

Reactive oxygen species (ROS) such as superoxide anion $\left(\mathrm{O}_{2}{ }^{-}\right)$are constantly generated in all aerobic biological systems, mainly by phagocytes through the respiratory burst (Babior 2002). This event is a crucial host defense against microorganisms which, paired with the non-oxidative phagocyte microbicidal mechanisms, determines death and elimination of many invader agents (Roos $\&$ Winterboum 2002). Superoxide dismutase (SOD) is a group of metalloenzymes that detoxify ROS through the conversion of $\mathrm{O}_{2}{ }^{-}$to hydrogen peroxide and molecular oxygen (Fridovich 1995). These enzymes are virtually present in all aerobic cells and their very high degrees of conservation is testament to their importance in cellular homeostasis. Three types of SOD isoenzymes occur in living cells, whose differences are due to their prosthetic fractions. In general eukaryotic cells contain MnSOD in the mitochondrial matrix and another isoenzyme, $\mathrm{Cu}, \mathrm{ZnSOD}$, which is located principally in the cytoplasm and in a lower extent in peroxissomes (Chaturvedi et al. 2001). The third type, FeSOD, occurs in photosynthetic organisms (Okamoto et al. 1996).

Discrimination of SOD isoenzymes is based on differential inhibition or inactivation by selective chemicals. Cyanide inactivates $\mathrm{Cu}, \mathrm{ZnSOD}$ while hydrogen peroxide inhibits irreversibly both FeSOD and Cu,ZnSOD (Mayer \& Falkinham. 1986).

Cryptococcus neoformans is an encapsulated yeast causing human disease with clinical manifestation that may vary from asymptomatic pulmonary infiltration to fatal disseminated infection, which is characterized by men-

Financial support: Fapesp, Capes

+Corresponding author: crpmicol@uol.com.br

Received 26 September 2005

Accepted 31 January 2006 ingitis. The capsular polysaccharide of this yeast contains antigenic determinants providing the basis for five serotypes, A ( $C$. neoformans var. grubii), D and $\mathrm{AD}(C$. neoformans var. neoformans), and $\mathrm{B}$ and $\mathrm{C}$ (C. neoformans var. gattii).

In the last two decades, a variety of fungal antioxidants have attracted considerable interest, largely arising from their hypothetical role as virulence associated factors. The biological roles of bacterial $\mathrm{Cu}, \mathrm{ZnSOD}$ contribute to the ability of invasive pathogens to survive to $\mathrm{O}_{2}{ }^{-}$ produced by macrophages and neutrophils during the respiratory burst (Hamilton \& Holdom 1997, Cox et al. 2003). This work evaluated the MnSOD and $\mathrm{Cu}, \mathrm{ZnSOD}$ activities from the three $C$. neoformans varieties. These strains were $C$. neoformans serotype A (ATCC 90112, USA), B (NIH-ICB 107, USA), C (NIH-ICB162, USA), AD (CBS-ICB 134, USA), D (NIH-ICB163, USA). They were subcultured in Sabouraud dextrose agar at $25^{\circ} \mathrm{C}$ during 24 $\mathrm{h}$, ressuspended in $2 \mathrm{ml}$ phosphate buffer saline solution (PBS) pH 7.8 and submitted to nitrogen cavitation $(1,250$ psi, $\left.20 \mathrm{~min}, 4^{\circ} \mathrm{C}\right)$ with the protease inhibitor phenylmethionylsulphonyl fluoride $(2.5 \mu \mathrm{g} / \mathrm{ml})$ and the peptidase inhibitor benzamidine $(1 \mu \mathrm{g} / \mathrm{ml})$. The efficiences of lysis were controlled by viability analysis with cell membrane integrity measured by methylene blue coloration (Mochaba et al. 1998). Total SOD activity was measured by the inhibition of the cytochrome $\mathrm{C}(7.5 \mu \mathrm{M})$ reduction, mediated via $\mathrm{O}_{2}{ }^{--}$that were generated by xanthine - xanthine oxidase system - and was monitored in a Hitachi model U-2000 dual beam spectrophotometer at $550 \mathrm{~nm}$. One unit of SOD was defined as the enzyme amount required to inhibit the reduction of cytochrome $\mathrm{C}$ by $50 \%$ at $25^{\circ} \mathrm{C}$. The activities of the isoforms MnSOD and $\mathrm{Cu}, \mathrm{ZnSOD}$ were determined by a modification of the method proposed by McCord and Fridovich (1968). The MnSOD activity was determined by the inhibition of the isoform $\mathrm{Cu}, \mathrm{ZnSOD}$ with the addition of $\mathrm{KCN}(5 \mathrm{mM})$ (Mayer \& Falkinham 1986). The $\mathrm{Cu}, \mathrm{ZnSOD}$ activity was 
determined by the difference between the total SOD and MnSOD activities. All samples were submitted to total protein determination using bovine serum albumin as standard and the final enzymes units (U) were plotted per mg of total protein (Bradford 1976). The data shown are means \pm sd from experiments performed in triplicate that were statistically analyzed using one way ANOVA and Bonferroni Multiple Comparisons Tests. $p<0.05$ was considered significant. The specific activities of total SOD and of the both isoenzymes MnSOD and $\mathrm{Cu}, \mathrm{ZnSOD}$ are shown the Tables I, II and Figure. C. neoformans var. gattii serotype $\mathrm{C}$ showed the higher total SOD activity. Var. grubii displayed the lower total SOD activity among the analyzed reference yeast strains with $(4 \pm 1) \mathrm{U}$ of $\mathrm{Cu}, \mathrm{ZnSOD} / \mathrm{mg}$ protein and $7 \mathrm{U}$ of $\mathrm{MnSOD} / \mathrm{mg}$ protein. Var. neoformans serotypes D and AD showed no significant differences in both isoenzymes. There were significant differences $(p<0.01)$ in MnSOD activity from the serotype $\mathrm{C}$ strain in comparison with all the other reference varieties tested. $\mathrm{Cu}, \mathrm{ZnSOD}$ showed differences $(p<$ 0.05 ) between A and D reference serotypes.

In recent studies, the variety gattii has been considered, as a separated species, C. gattii (C. bacillisporus) (Sorrel 2001, Barreto de Oliveira et al. 2004). There are a number of clear dissimilarities among $C$. neoformans var. grubii, var. neoformans and var. gattii $(C$. gattii $=C$. bacillisporus), including differences in biochemistry, environmental source, DNA composition, number of chromossomes, clinical manifestation of the disease, and response to antifungal therapy. There are differences with regard to the enzyme production in the three varieties, although there is only very limited data on the differences among individual enzyme system (Lacaz et al. 2002). It is shown here that SOD activity is one biochemical parameter to be consider among these discrepances. $C$. neoformans var. gattii predominantly infects immunocompetent individuals, whereas var. grubii and neoformans

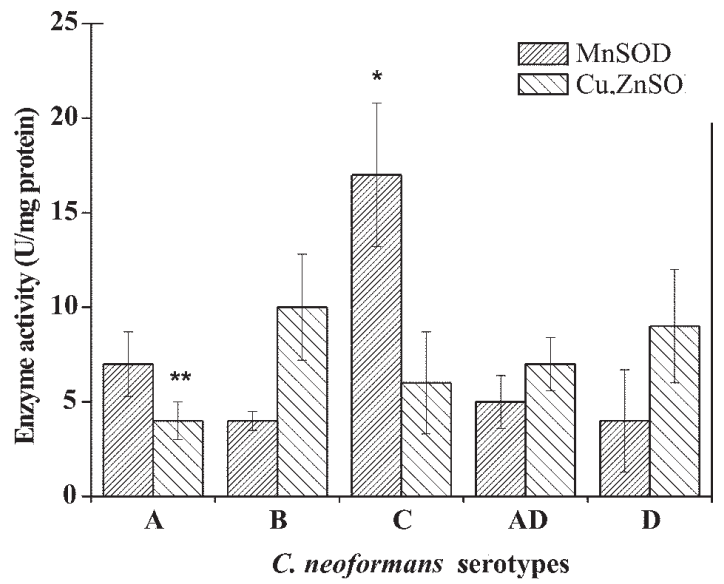

MnSOD and $\mathrm{Cu}, \mathrm{ZnSOD}$ activities in five reference serotypes of Cryptococcus neoformans. Cultured $C$. neoformans cells were lysed by nitrogen cavitation and both superoxide dismutase isoenzymes were determined. Results expressed as means $\pm \mathrm{sd}, \mathrm{n}=3 ; * p<0.01$ serotype $\mathrm{C}$ against all other serotypes and $* * p<0.05$ serotype A against serotype $\mathrm{D}$ in respect to the same isoenzyme.

are common in immunocompromised individuals. The mechanism of diferences in host prediction remain largely unknown, except for two experimental studies that reported that $C$. neoformans var. gattii inhibits phagocyte response whereas the other two varieties are readily killed by ROS that are released by phagocytic cells. It was hypothesized that this difference could result from innate diverse responses among the antioxidants of these varieties (Chaturvedi et al. 2001). The comparison of the total SOD from the three varieties of $C$. neoformans provides further insight into the biochemical relationship among them. We refined these studies showing here that the isoenzymes $\mathrm{Mn}$ - and $\mathrm{Cu}, \mathrm{ZnSOD}$ vary significantly among

TABLE I

Total superoxide dismutase and isoenzymes MnSOD and Cu,ZnSOD activities in Cryptococcus neoformans reference strains

\begin{tabular}{|c|c|c|c|c|c|}
\hline Strain & ATCC90112 & NIH-ICB107 & NHI-ICB162 & CBS-ICB134 & NIH-ICB163 \\
\hline Serotype & A & $\mathrm{B}$ & $\mathrm{C}$ & $\mathrm{AD}$ & $\mathrm{D}$ \\
\hline Varieties & grubii & gattii & gattii & neoformans & neoformans \\
\hline Total SOD $^{a}$ & $11 \pm 2.8$ & $14 \pm 0.5$ & $23 \pm 10.6^{*}$ & $12 \pm 0.5$ & $13 \pm 8.8$ \\
\hline $\operatorname{MnSOD}^{a}$ & $7 \pm 1.7$ & $4 \pm 0.5$ & $17 \pm 3.8$ & $5 \pm 1.4$ & $4 \pm 2.7$ \\
\hline $\mathrm{Cu}, \mathrm{ZnSOD}^{a}$ & 4 & 10 & 6 & 7 & 9 \\
\hline
\end{tabular}

$a$ : activity (U/mg protein); results (in triplicate) are expressed as means $\pm \mathrm{sd},{ }^{*} p<0.01$ (serotype C against all other serotypes).

TABLE II

Total superoxide dismutase and isoenzymes MnSOD and Cu,ZnSOD activities in nine Cryptococcus neoformans strains

\begin{tabular}{lccccccccc}
\hline Strain & ICB154 & ICB170 & ICB107A & ICB184 & ICB88 & ICB108 & ICB134A & ICB173 & ICB110 \\
\hline Serotype & A & A & B & B & C & C & AD & D & D \\
Varieties & grubii & grubii & gattii & gattii & gattii & gattii & neoformans & neoformans & neoformans \\
Total SOD $^{a}$ & 15 & $62 \pm 1$ & $52.5 \pm 10.5$ & $33 \pm 0.5$ & $160 \pm 1.5 *$ & $186^{*}$ & 48 & $51.5 \pm 10.5$ & 16 \\
MnSOD $^{a}$ & $10.5 \pm 0.5$ & $9 \pm 1$ & $11 \pm 0.5$ & 23 & 75 & $32 \pm 1.5$ & 36 & $14 \pm 0.5$ & 11 \\
$\mathrm{Cu}_{\text {ZnSOD }}{ }^{a}$ & 4.5 & 53 & 41.5 & 10 & 85 & 154 & 12 & 37.5 & 5 \\
\hline
\end{tabular}

$a$ : activity (U/mg protein); results (in triplicate) are expressed as means $\pm \mathrm{sd}, * p<0.05$ (serotype $\mathrm{C}$ against all other serotypes). 
all serotypes. After phagocytosis by polymorphonuclear cells or macrophages, pathogens in the phagolysosomes are exposed to a variety of ROS, including $\mathrm{O}_{2}{ }^{-}$. . Microorganism SODs are important housekeeping antioxidants and have an additional hypothetical role in virulence. Despite these enzymes have been biochemically characterized from some fungus as Aspergillus and Cryptococcus, there is as yet no strong evidence that these enzymes are involved in pathogenicity. The $\mathrm{Cu}, \mathrm{ZnSOD}$ was previously pointed in $C$. neoformans as the more abundant form of the enzyme, and its cytoplasmic location was thought to be more relevant for a possible protection against phagocyte-derived ROS (Chaturvedi et al. 2001). Our results showed a discrepancy from these results in respect to serotype $\mathrm{C}$, although we confirmed the higher total SOD activity inside this serotype. Previous report showed similarities with regard to amino acid sequences among $\mathrm{Cu}, \mathrm{ZnSOD}$ isolated from C. neoformans and from other organisms, including fungus, and there was no homology with the previous described $C$. neoformans MnSOD with other representatives of this isoform of the enzyme. It was noted that, while KCN inhibited both cryptococcal $\mathrm{Cu}, \mathrm{ZnSOD}$ enzymes, another previously defined inhibitor of the isoenzyme, the $\mathrm{Cu}^{2+}$ chelator diethyldithiocarbamate (DDC) had a significant inhibitory effect only on the C. neoformans var. gattii SOD. This might suggest that in the C. neoformans var. neoformans enzyme, in contrast to the $C$. neoformans var. gattii, the $\mathrm{Cu}^{2+}$ is inaccessible to DDC indicating a possible structural differences between the two enzymes. These apparent differences in structure are surprising for fungi that still today are classified as varieties from the same species. In addition, the SOD from all the $C$. neoformans varieties displayed some apparent $\mathrm{pH}$ dependence, in contrast to previously described fungal SOD (Hamilton \& Holdom 1997). The characterization of a $\mathrm{Cu}, \mathrm{ZnSOD}$ gene knock-out $C$. neoformans mutant has been realized (Chaturvedi et al. 2001). In the mutant for this gene, no defects were seen in growth, capsule synthesis, mating, sporulation but it was markedly attenuated in virulence in a mouse model and it was significantly susceptible to in vitro killing by human neutrophils. This report constituted the first instance in which SOD has been directly implicated in the virulence of a fungal pathogen. In some bacteria, SOD has been shown to be important for survival within macrophages and for virulence in animal models. It is known that $C$. neoformans resides in macrophages during many stages of experimental and human infections and that the resistance to macrophage killing, in first instance mediated by SOD activity may be important for virulence in this fungus (Chaturvedi et al. 1996).

The prevalence of invasive fungal infections is increasing simultaneously in occurrence to the growing of immunocompromised patient numbers. So, it is important to develop new strategies to control fungal invasions. As C. neoformans is a successful intracellular pathogen, it is believed that it must have efficient mechanisms for the detoxification of ROS. It seems plausible that the role of microbial SOD in pathogenicity should be closely associated with defense against phagocyte attack (Chaturvedi et al. 1996).
In a first moment we evaluated the activities of SOD isoenzymes of 14 C. neoformans strains but additional studies have already being performed to give support to this previous one. Then, detailing antioxidant enzymes from these fungi could provide insights that can help us in the diagnosis and treatment of this important human disease.

\section{REFERENCES}

Babior BM 2002. The Neutrophil NADPH Oxidase. Arch Biochem Biophysics 397: 342-344.

Barreto de Oliveira MT, Boekhout T, Theelen B, Hagen F, Baroni FA, Lazera MS, Lengeler KB, Heitman J, Rivera IN, Paula CR 2004. Cryptococcus neoformans shows a remarkable genotypic diversity in Brazil. J Clin Microbiol 42: 13561359.

Bradford M 1976. A rapid and sensitive method for the quantification of microgram quantities of protein utilizing the principle of protein-dye binding. Anal Biochem 72: 248-254.

Chaturvedi S, Hamilton AJ, Hobby P, Zhu G, Lowry CV, Chaturvedi V 2001. Molecular Cloning, phylogenetic analysis and three-dimensional modeling of $\mathrm{Cu}, \mathrm{Zn}$ superoxide dismutase (CnSOD1) from three varieties of Cryptococcus neoformans. Gene 268: 41-51.

Chaturvedi V, Wong B, Newman SL 1996. Oxidative killing of Cryptococcus neoformans by human neutrophils: evidence that fungal manitol protects by scavenging reactive oxygen intermediates. J Immunol 156: 3836-3840.

Cox GM, Harrison TS, McDade HC, Taborda CP, Heinrich G, Casadevall A, Perfect JR 2003. Superoxide dismutase influences the virulence of Cryptococcus neoformans by affecting growth within macrophages. Infect Immun 20: 173-180.

Fridovich I 1995. Superoxide radical and superoxide dismutases. Ann Rev Biochem 64: 97-112.

Hamilton AJ, Holdom MD 1997. Biochemical Comparison of the $\mathrm{Cu}, \mathrm{Zn}$ Superoxide Dismutases of Cryptococcus neoformans var. neoformans and Cryptococcus neoformans var. gattii. Infect Immun 65: 488-494.

Lacaz CS, Porto E, Martins JEC, Heins-Vaccari EM, Melo NT 2002. Tratado de Micologia Médica, $9^{\mathrm{a}}$ ed., Sarvier, São Paulo, 1104 pp.

Mayer BK, Falkinham JO 1986. Superoxide dismutase activity of Mycobacterium avium and $M$. intracellulare, and $M$. scrofulaceum. Infect Immun 53: 631-635.

McCord JM, Fridovich I 1968. The reduction of cytochrome C by milk xanthine oxidase. J Biol Chem 243: 5753-5760.

Mochaba F, O’Connor ES, Axell BC 1998. Practical Procedures to Measure Yeast Viability and Vitality Prior to Pitching. Am Soc Brew Chem 56: 1-6.

Okamoto OK, Asano CS, Aidar E, Colepicolo P 1996. Effects of Cadmium on growth and superoxide dismutase activity of the marine microalga Tetraselmis gracilis (Prasinophyceae). J Phycol 32: 74-79.

Roos D, Winterbourn C 2002. Lethal weapons. Science 296: 669-671.

Sorrel TC 2001. Cryptococcus neoformans variety gattii. Med Mycol 39: 155-168. 